\title{
Surgical Site Infection among Patients Undergone Orthopaedic Surgery at Muhimbili Orthopaedic Institute, Dar es Salaam, Tanzania.
}

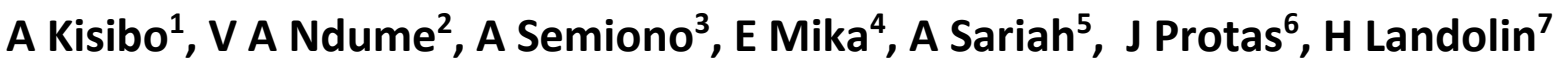 \\ ${ }^{1}$ Hubert Kairuki Memorial University (HKMU), Faculty of Nursing Dar es Salaam Tanzania. \\ ${ }^{2}$ Dar es Salaam Institute of Technology (DIT) Department of Computer Studies Tanzania. \\ ${ }^{3}$ Kairuki School of Nursing.(KSN), Department of Maternal and Child Health, Dar es Salaam, \\ Tanzania. \\ ${ }^{4}$ Hubert Kairuki Memorial University (HKMU), Department of Fundamental of Nursing and \\ Basic Sciences, Dar es Salaam, Tanzania \\ ${ }^{5}$ Hubert Kairuki Memorial University (HKMU), Department of Maternal and Child Health, Dar \\ es Salaam, Tanzania. \\ ${ }^{6}$ Hubert Kairuki Memorial University (HKMU), Department of Community Health Nursing, \\ Dar es Salaam, Tanzania. \\ ${ }^{7}$ Muhimbili National Hospital (MNH), Department of Surgery, Dar es Salaam, Tanzania \\ Correspondence to: Joyce Protas, Email: mlay.joyce@yahoo.com \\ https://dx.doi.org/10.4314/ecajs.v22i1.7
}

Background: The aim of this study was to determine prevalence and factors associated with surgical site infection at Muhimbili Orthopedic Institute.

Method: This was a cross-sectional study conducted at Muhimbili Orthopaedic Institute (MOI) in Dar es Salaam, from August, 2015 to October 2015. Convenience sampling technique was used to recruit postoperative patients for this study. Standardized questionnaires were used to obtain demographic, social, and clinical information from respondents. Determination of the relationship between outcome and exposure variables was done using chi square test. Multivariate logistic regression was used to measure the association after controlling for confounders. Odds ratio corresponding to 95\% confidence interval with a $p$ value of $\leq 0.05$ was considered significant.

Results: Out of 300 study participants 75(25.0\%) had surgical site infection. This was highly determined by more than 2 hours length of surgical procedure (AOR=1.4; 95\% Cl 1.14-6.69; $P$ value $=0.05)$, none prophylactic use of antibiotics $(A O R=3.4 ; 95 \% \mathrm{Cl}$ 1.6-7.78; $P$ value=0.03), more than one week stay before surgery $(A O R=3.3 ; 95 \% \mathrm{Cl}$ 2.24-3.34; $P$ value $=0.00$ ).

Conclusion: The overall prevalence of surgical site infection at Muhimbili Orthopedic Institute was high. This was associated with more than 2 hours length of surgery, lack of prophylaxis use, and pre-operative hospital stay.

Introduction

Surgical site infections (SSIs) in orthopaedic surgery are globally common and continue to be a major problem among orthopaedic patients ${ }^{1-3}$. A surgical site infection is clinically defined as presence of pain at a surgically created wound, which is accompanied by erythema, induration and local tenderness or presence of purulent discharge at wound site ${ }^{1,4}$. Surgical 
site infection (SSI) is the infection which occurs within 30 days after surgery or one year if implant left in the site after procedure $(5,-7$,$) . Worldwide, orthopaedic SSI rates range$ between 1.4 and $41.9 \% 3,8$. Surgical site infections in orthopedic practice can have significant effects on quality of life for the patient. They are associated with considerable morbidity, financial burden to the patient and health care providers and extended hospital stay. Other effects of SSIs include revision surgery, delayed wound healing, increased use of antibiotics, all of which have a significant impact on patients and the cost of health care $^{1-, 5-11}$.

To alleviate the problem of SSIs among orthopaedic cases several measures have been recommended and taken into action. These include appropriate timing of prophylactic antibiotics administration at about $\mathbf{3 0}$ minutes prior incision, use of appropriate antiseptic agents and techniques for surgical site skin preparation, reduction of movements and number of staff in the operating rooms and protection of incision site with sterile dressings $3,5,6$. Little is known about the magnitude and risk factors for SSIs among orthopaedic cases in our environment as a limited number of studies about SSIs have been conducted in Tanzania which mainly based on general surgical patients ${ }^{12}$. More over there is no recent survey done on SSI in orthopaedic patients in our setting. Therefore this study determined the magnitude and factors that contribute to post operative surgical site infection in patients with skeletal trauma at Muhimbili orthopaedic institute.

\section{Patients and Methods}

This study was conducted at Muhimbili orthopedic Institute which is the main referral hospital for orthopedic cases in Dar es Salaam, Tanzania. This was a hospital based crosssectional study conducted from August, 2015 to October 2015. The study population included patients who had undergone long bones surgical operation admitted in the wards and those attended at the out patients department (OPD) for follow up. Both elective and emergency operated patients were involved. Patients who had initial trauma surgery at another hospital or those who presented with SSIs after being treated at an outside hospital, those with metastatic fractures, back, spine were not included as they fall under different realms. Hand and finger injuries were also excluded from the study. The sample size was calculated to be 300 participants.

Data collection was done from Monday to Friday from 8 am to $2 \mathrm{pm}$ and the convenience method of sampling was used to select participants.All post operative patients who met the inclusion criteria were included in the study. Prior to an interview informed consent was obtained and then by using a standardized questionnaire a participant was asked a series of closed questions about their demographic, clinical and social background information which included the age, sex, marital status, education level, length of surgical procedure, antibiotic use, health condition before surgery, place of dressing, HIV status, length of hospitalization, and time of stay prior surgery. Then the wound site was examined for at least one of the following signs or symptoms of wound infection: pain or tenderness, localized swelling, redness and purulent discharge ${ }^{4,5}$. The patients ' files were also reviewed. Data entry and analysis was carried out using SPSS computer software version 20 and frequency tables 
were obtained for all study variables. Descriptive analysis was done by using frequencies, percentages and means where appropriate. Association between explanatory variable and the outcome of interest was done using $2 \times 2$ tables. Multivariate logistic regression analyses were used to examine independent variables that influence the outcome variable. Odds Ratios with corresponding $95 \%$ confidence interval are presented. All independent variables found significant in the univariate analysis were included in the multivariate analysis. A P-value of $\leq 0.05$ was considered statistically significant. Ethical clearance for conducting this research was obtained from the Institutional Research Board of the Hubert Kairuki Memorial University and the permission to carry out the study was obtained from the Muhimbili Orthopedic Institute administration.

\section{Results}

The study involved 300 patients. Most of cases were aged below 46 years and the peak age was under 30 years of age. The median age was 46.5(15-78) years and each group of males and females accounted for almost a half of the study population. About $159(53.0 \%)$ participants were married and $125(41.7 \%)$ had primary education level (Table1).

Table 1. Frequency Distribution of Demographic Data $(\mathrm{N}=300)$.

\begin{tabular}{|c|c|c|}
\hline Demographic characteristics & Frequency & Percentage \\
\hline \multicolumn{3}{|l|}{ Age } \\
\hline $15-30$ & 135 & 45.0 \\
\hline $31-46$ & 102 & 34.0 \\
\hline $47-62$ & 48 & 16.0 \\
\hline $63-78$ & 15 & 5.0 \\
\hline \multicolumn{3}{|l|}{ Sex } \\
\hline Male & 152 & 50.7 \\
\hline Female & 148 & 49.3 \\
\hline \multicolumn{3}{|l|}{ Marital status } \\
\hline Married/living with partner & 159 & 53.0 \\
\hline $\begin{array}{l}\text { Not married (single, divorced, widow, } \\
\text { widower) }\end{array}$ & 141 & 47.0 \\
\hline \multicolumn{3}{|l|}{ Education level } \\
\hline Primary & 125 & 41.7 \\
\hline Secondary & 89 & 29.7 \\
\hline Collage/University & 78 & 26.0 \\
\hline No education & 8 & 2.7 \\
\hline
\end{tabular}


Table 2. Frequency Distribution of Clinical Characteristics of Study Participants

\begin{tabular}{|c|c|c|}
\hline Clinical characteristics & Frequency & Percentage \\
\hline \multicolumn{3}{|c|}{ Length of surgical procedure } \\
\hline Two hours & 208 & 69.3 \\
\hline More than two hours & 92 & 30.7 \\
\hline \multicolumn{3}{|l|}{ Use of prophylaxis } \\
\hline Yes & 270 & 90.0 \\
\hline No & 30 & 10.0 \\
\hline \multicolumn{3}{|c|}{ Health Condition before surgery } \\
\hline Sick & 82 & 27.3 \\
\hline Well & 218 & 72.7 \\
\hline \multicolumn{3}{|l|}{ Place of dressing } \\
\hline Hospital & 276 & 92.0 \\
\hline Home & 24 & 8.0 \\
\hline \multicolumn{3}{|l|}{ HIV Status } \\
\hline Positive & 34 & 11.3 \\
\hline Negative & 201 & 67.0 \\
\hline Not tested & 65 & 21.7 \\
\hline \multicolumn{3}{|l|}{ Length of hospitalization } \\
\hline Less than seven days & 217 & 72.3 \\
\hline More than seven days & 81 & 27.0 \\
\hline More than a month & 2 & 0.7 \\
\hline \multicolumn{3}{|c|}{ Time of Stay before Surgery } \\
\hline Two days & 82 & 27.3 \\
\hline More than a week & 125 & 41.7 \\
\hline More than a month & 32 & 10.7 \\
\hline Emergency & 61 & 20.3 \\
\hline
\end{tabular}

The proportion of surgical wound infection among study participants.

Out of 300 study participants surgical wound infection was observed in 75(25.0\%) cases. Surgical site infection was common among those aged above 46 years and in HIV negative patients ( $P$ values $>0.087$ ). Females, unmarried participants, and those with no formal education commonly developed SSI ( $P$ values $<0.049$ ). But on multivariate logistic analysis this observation was statistically insignificant. The duration of surgery in most of patients, $69.3 \%$ (208/300), was less than 2 hours and wound sepsis occurred frequently among those who were operated for more than two hours, 35.5\% (33/92). This finding was statistically significant even on multivariate logistic regression analysis.

The majority of cases, $90 \%$ (270/300), were given prophylactic antibiotics prior incision. SSI occurred commonly among individuals who did not receive prophylactic antibiotics, $56.7 \%$ ( $17 / 30)$, and statistically this result was significant even after controlling for confounders. 
Table 3. Factors associated with Surgical site infection, $\mathrm{N}=300$

\begin{tabular}{|c|c|c|c|c|}
\hline Factors & Sepsis (\%) & Total (\%) & $x^{2}$ & p-value \\
\hline \multicolumn{5}{|l|}{ Age } \\
\hline $15-30$ & $30(22.2)$ & 135(100.0) & & \\
\hline $31-46$ & $22(21.6)$ & $102(100.0)$ & 6.73 & 0.087 \\
\hline $47-62$ & $16(33.3)$ & $48(100.0)$ & & \\
\hline $63-78$ & $7(46.7)$ & $15(100.0)$ & & \\
\hline \multicolumn{5}{|l|}{ Sex } \\
\hline Male & $30(19.7)$ & $152(100.0)$ & 11.12 & 0.025 \\
\hline Female & $45(30.4)$ & $148(100.0)$ & & \\
\hline \multicolumn{5}{|l|}{ Marital status } \\
\hline Married/living with partner & $36(22.6)$ & $159(100.0)$ & 9.17 & 0.049 \\
\hline Not married & $39(27.6)$ & $141(100.0)$ & & \\
\hline \multicolumn{5}{|l|}{ Education level } \\
\hline Primary & $30(24.0)$ & $125(100.0)$ & & \\
\hline Secondary & $21(23.6)$ & $89(100.0)$ & 11.01 & 0.026 \\
\hline Collage/University & $18(23.1)$ & $78(100.0)$ & & \\
\hline No education & $6(75.0)$ & $8(100.0)$ & & \\
\hline \multicolumn{5}{|l|}{ Length of surgical procedure } \\
\hline Two hours & $42(20.2)$ & $208(100.0)$ & 8.36 & 0.006 \\
\hline More than two hours & $33(35.9)$ & $92(100.0)$ & & \\
\hline \multicolumn{5}{|l|}{ Use of prophylaxis } \\
\hline Yes & $58(21.5)$ & $270(100.0)$ & 17.83 & 0.00 \\
\hline No & $17(56.7)$ & $30(100.0)$ & & \\
\hline \multicolumn{5}{|c|}{ Health education before surgery } \\
\hline Sick & $31(37.8)$ & $82(100.0)$ & 9.87 & 0.003 \\
\hline Well & $44(20.2)$ & $218(100.0)$ & & \\
\hline \multicolumn{5}{|l|}{ Place of dressing } \\
\hline Hospital & $65(23.6)$ & $276(100.0)$ & 3.87 & 0.049 \\
\hline Home & $10(41.7)$ & $24(100.0)$ & & \\
\hline \multicolumn{5}{|l|}{ HIV Status } \\
\hline Positive & $8(23.5)$ & $34(100.0)$ & & \\
\hline Negative & $55(27.4)$ & $201(100.0)$ & 4.3 & 0.381 \\
\hline Not tested & $12(18.5)$ & $65(100.0)$ & & \\
\hline \multicolumn{5}{|l|}{ Length of hospitalization } \\
\hline Less than seven days & $22(10.1)$ & $217(100.0)$ & 19.58 & 0.00 \\
\hline More than seven days & $53(65.4)$ & $81(100.0)$ & & \\
\hline More than a month & $0(0.0)$ & $2(100.0)$ & & \\
\hline \multicolumn{5}{|l|}{ Time of stay before surgery } \\
\hline Two days & $8(9.8)$ & $82(100.0)$ & & \\
\hline More than a week & $43(34.4)$ & $125(100.0)$ & & \\
\hline More than a month & $10(31.3)$ & $32(100.0)$ & 19.48 & 0.00 \\
\hline Emergency & $14(23.0)$ & $61(100.0)$ & & \\
\hline
\end{tabular}


Table 4. Multivariate Logistic Regression on Factors Associated with SSI ( $n=300)$

\begin{tabular}{|c|c|c|c|c|c|}
\hline Factors & Sepsis (\%) & Total (\%) & AOR & $95 \% \mathrm{Cl}$ & P-value \\
\hline \multicolumn{6}{|l|}{ Sex } \\
\hline Male & $30(19.7)$ & $152(100.0)$ & 1 & & \\
\hline Female & $45(30.4)$ & $148(100.0)$ & 1.624 & $0.343-1.136$ & 0.123 \\
\hline \multicolumn{6}{|l|}{ Marital status } \\
\hline Married/living with partner & $36(22.6)$ & 159(100.0) & 1 & & \\
\hline Not married & $39(27.6)$ & 141(100.0) & 1.473 & $0.45-5.019$ & 0.535 \\
\hline \multicolumn{6}{|l|}{ Education level } \\
\hline No education & $6(75.0)$ & $8(100.0)$ & 1 & & \\
\hline Primary & $30(24.0)$ & $125(100.0)$ & 0.208 & $0.034-1.261$ & 0.08 \\
\hline Secondary & $21(23.6)$ & $89(100.0)$ & 0.205 & $0.033-1.252$ & 0.08 \\
\hline Collage/University & $18(23.1)$ & $78(100.0)$ & 0.190 & $0.030-1.220$ & 0.07 \\
\hline \multicolumn{6}{|l|}{$\begin{array}{l}\text { Length of } \\
\text { surgical procedure }\end{array}$} \\
\hline Two hours & $42(20.2)$ & $208(100.0)$ & 1 & & \\
\hline More than two hours & $33(35.9)$ & $92(100.0)$ & 1.4 & $1.14-6.69$ & 0.05 \\
\hline \multicolumn{6}{|l|}{ Use of prophylaxis } \\
\hline Yes & $58(21.5)$ & $270(100.0)$ & 1 & & \\
\hline No & 17(56.7) & $30(100.0)$ & 3.4 & 1.6-7.78 & 0.03 \\
\hline \multicolumn{6}{|l|}{$\begin{array}{l}\text { Health condition before } \\
\text { surgery }\end{array}$} \\
\hline Well & $44(20.2)$ & $218(100.0)$ & 1 & & \\
\hline Sick & $31(37.8)$ & $82(100.0)$ & 1.14 & $0.04-1.15$ & 0.093 \\
\hline \multicolumn{6}{|l|}{ Place of dressing } \\
\hline Hospital & $65(23.6)$ & $276(100.0)$ & 1 & & \\
\hline Home & $10(41.7)$ & $24(100.0)$ & 1.04 & $0.467-1.66$ & 0.202 \\
\hline \multicolumn{6}{|l|}{ Time of stay before surgery } \\
\hline Two days & $8(9.8)$ & $82(100.0)$ & 1 & & \\
\hline More than a week & $43(34.4)$ & $125(100.0)$ & 3.3 & $2.24-3.34$ & 0.00 \\
\hline More than a month & $10(31.3)$ & $32(100.0)$ & 2.8 & $1.13-3.36$ & 0.001 \\
\hline Emergency & $14(23.0)$ & $61(100.0)$ & 1.6 & $0.99-1.8$ & 0.24 \\
\hline
\end{tabular}

Wound dressing in the majority of patients was being done in the health facility, $92.0 \%$ (276/300), SSI affected commonly those participants who were being cared for their wounds at their homes, $417 \%(10 / 24)$. But this observation was statistically insignificant when analyzed by multivariate logistic regression. Surgical site infection was common among 
those who had no HIV infection 27.4\% (55/201). Nevertheless this finding was not statistically significant. A total of $83(27.7 \%)$ of the 300 patients stayed in the hospital for less than 7 days. The majority (52.4\%) Ot cases stayed for more than 1 week in the hospital before surgery. Prolonged hospitalization for more than one week duration of hospital stay prior surgery are statistically associated with development of SSI (Tables 3 and 4).

\section{Discussion}

Surgical site infection is a major problem among orthopaedic patients ${ }^{1,5}$. The prevalence of SSI in the current study is higher than that reported by other authors $2,3,4,6,7,8,9,10$. However, similar prevalence of SSI was observed in other studies done by ${ }^{1,12}$. The reasons for high prevalence of SSI in this study could be due to inadequate adherence to aseptic techniques perioperative, a significant number of cases having contaminated wounds during surgery, overcrowding of patients in the wards causing high cross infection, inadequate knowledge and poor adherence to aseptic practice in wound care among health personnel causing wound contamination and infection.

As regards to studied factors that contribute to SSI various factors were significantly associated with occurrence of SSI. There is a direct relationship between development of surgical site infection and the length of surgery. Orthopaedic surgeries done for more than 2 hours are at higher risk of infection ${ }^{3,7,10,11,12,13,14}$. Similar finding was noted in the present study. High risk of infection in prolonged surgeries may be due to increased tissue and surgical instruments exposure to the environmental bacteria, surgical team exhaustion enhancing poor adherence to aseptic techniques and decreasing of patient's microorganisms systemic defenses as same as it was explained by others ${ }^{7,11}$.

The use of anti microbial prophylaxis in orthopaedic surgery is important as it helps to minimize or eradicate endogenous microbes and prevent SSI. Prophylactic antibiotics help to decrease SSI rates to $1-3 \%$ compared with $4-8 \%$ without prophylactic antibiotics. Timing of antimicrobial prophylaxis is extremely important as it is related to the rate of SSI. Antimicrobial prophylaxis should be administered ideally within 30 minutes to 1 hour prior incision ${ }^{(5,15)}$. The above explanation given by ${ }^{(6)}$ is confirmed by this survey as most of the patients who did not use prophylactic antibiotics developed SSI and equal observations were reported by other surveyors ${ }^{2,14}$.

Prolonged hospital stay generally pause a higher risk of developing surgical site infection $2,4,5,9,13,14$. This is evidenced by the findings of this current analysis whereby prolonged hospitalization for more than a week was noted to be highly a risk factor for SSI. In particular to preoperative duration of hospital stay the present study observed a significant association between prolonged preoperative length of stay for more than 7 days and occurrence of SSI which is corresponding to the findings obtained in other previous studies ${ }^{2,11}$. The likely explanation for these observations may be increased preoperative hospital stay period predisposes to skin colonization by hospital microbes that are resistant to antibiotics and so it is important to minimize preoperative hospitalization period in order to lower SSI rate ${ }^{2,8,11}$. However ${ }^{(8)}$ found preoperative length of hospitalization not to have 
any association with development of SSI. This difference might be reflecting low rate of hospital acquired cross infection or absence of overcrowding there setting. It may also be due to the fact that compared their cases based on more or less than 4 days pre operative hospital stay while in the current and other studies based on seven days.

Although SSI was high in aged patients ( $>45$ years of age) in the present analysis, but this finding was not statistically significant likewise the findings of the study done by $2,3,10$ indicating age alone not to be a risk factor for SSI. However other authors ${ }^{1,11,13}$ stress old age to be a risk factor for development of SSI probably mainly due to the elderly associated morbid conditions like depression of the body immunity, reduced appetite causing poor nutrition status and diabetes mellitus ${ }^{11}$.

Post surgical appropriate wound care is among the important aspects in reduction of SSI rate. Experts reports that inappropriate wound care contributes to as high as $10 \%$ of SSI ${ }^{14,16}$. In this survey some patients were being cared for their wounds at their home places by health care personnel and this was not associated with occurrence of SSI depicting place of wound dressing not to be a mere risk factor for SSI rather than aseptic dressing techniques and other already explained factors

The presence of the underlying disease processes, systemic infections, metabolic imbalance or endocrine disorders increases the incidence of postoperative SSI. Failure of the immune system in HIV infected patients increase the possibility of developing surgical site infections post operatively $17,18,19$. In the current study HIV infection was not statistically significantly associated with development of SSI as similar as it was documented by other surveyors (20, ${ }^{21)}$ reflecting HIV per se not to be a major risk factor for SSI development in orthopaedic practice. However, this observation might be due to small sample size analysed in these studies. In this analysis gender had no influence on occurrence of SSI as same as it was documented in other studies, 4, 5, 7, 8,11 13. Also in this study, marital status and level of education were not found to influence development of SSI.

\section{Conclusion and Recommendation.}

Surgical site infection rate is high at $\mathrm{MOI}$ and the independent risk factors for SSI were length of surgical procedure for more than two hours, lack of use of prophylactic antibiotics, prolonged pre operative hospital stay and prolonged hospital stay for more than 1 week. It is therefore recommended that the hospital staff to adhere to aseptic practices and appropriate use of prophylactic antibiotics. The hospital management should try to set the environment that will ensure that cases are managed promptly and discharged home early to minimize acquisition of cross infection.

\section{References}

1. Sabir MR, Iqbar MZ, Malick MR. Surgical site infections in orthopaedic patients; a public health dilemma.PJMHS online 
2. Starcevic S, Munitlak S, Mijoric B, Mikic D, Suljagic V. Surgical site infection surveillance in orthopaedic patients in the military medical academy, Belgrade. Vojnosanit pregl 2015; 72 (6):499-504.

3. Al-Mulhim FA, Baragbah MA, Sadat-Ali M, Alomran AS, Azam MQ. Prevalence of surgical site infection in orthopaedic surgery: A 5 years analysis. Int Surg 2014; 99 (3):264-268.

4. Afifi IK, Baghagho EA. Three months study of orthopaedic surgical site infections in an Egyptian university hospital. Int J Infect Control 2010; 6 (1):1-6.

5. Maksimovic J, Markovic-Denic L, Bumbasirevic M, Marinkovic J, Vlajinac H. Surgical site infections in orthopaedic patients: Prospective cohort study. Croat Med J 2008; 49(1):58-65.

6. Rajdi M, Aini F, Fauziyah S. Evaluation of antibiotic prophylaxis administration at the orthopaedic surgery clinic of tertiary hospital in Jarkata, Indonesia. Asian Pac J Trop Dis 2014; 4 (3): 190-193.

7. Bachoura A, Guitton TG, Smith RM, Vrahas MS, Zurakowski D, Ring D. Infirmity and injury complexity are risk factors for surgical site infection after operative fracture care. Clin Orthop Relat Res 2011; 469 (9):2621-2630.

8. Ercole FF, Franco LMC, Macierina TGR, Wenceslau LCC, Resende HIN, Chianca TCM. Risk of surgical site infection in patients undergoing orthopaedic surgery. Rev.LatinoAm Enfermagem 2011; 19 (6): 1362-1368.

9. Rajkumari N, Gupta AK, Mathur P, Trikha V, Sharma V, Farooque K, Misra MC. Outcomes of surgical site infections in orthopaedic trauma surgeries in a tertiary care center in India J Postgrad Med 2014; 60(3):254-259.

10. Mabit C, Marcheix PS, Mounier M, Dijoux P, Pestourie N, Bonnevialle P et al. Impact of a surgical site infection (SSI) surveillance program in orthopaedics and traumatology. Orthopaedic and Traumatology: Surgery and Research 2012; 98 (3): 690-695.

11. Ikaenyi UOE, Chokwuka CN, Chukwuanukwu TOG. Risk factors for surgical site infections following clean orthopaedic operations. Nigerian Journal of clinical practice 2013; 16(4): 443-447.

12. Manyahi J.Bacteriologiacl spectrum of post operative wound infection and their antimicrobial in tertiary hospitals, Dar es salaam, Tanzania

13. Abdul-Haleim KM, Ibraheim ZAK, El-Tahlawy EM. Surgical site infections and associated risk factors in Egyptian orthopaedic patients. Journal of American science 2010; 6(7): 272-280.

14. Thu LTA, Ewald B, Dibley MJ, Tien NP, Lam LD. Incidence of surgical site infections and accompanying risk factors in Vietnamese orthopaedic patients. J Hosp Infect 2005; 60 (4):360-367.

15. Ahmed M,Alam NS,Khan O, Manzar S.Post operative wound infection.Surgeon's Dilema.Pakistan Journal of Surgery 2007;23(1) 41-47

16. Uckay I, Hoffmeyer P, Lew D, Pittet D. Prevention of surgical site infections in orthopaedic surgery and bone trauma: State of the art update. Journal of hospital infection 2013; 84 (1): 5-12. 
17. Abalo A, Patassi A, James YE, Walla A, Sangare A, Dossim A. Risk factors for surgical wound infection in HIV- positive patients undergoing surgery for ortopaedic trauma. Journal of orthopaedic surgery 2010; 18(2):224-227.

18. Zhang L, Liu BC, Zhang XY, Li L, Xia XJ, Guo RZ. Prevention and treatment of surgical site infection in HIV- infected patients. BMC infectious Diseases 2012; 12(115): 1-4.

19. Osakwe JO,Nnaji GA,Osakwe RC,Agu U, and Mosanya JTRole of premorbid status and wound related facttos in surgical site infection in a tertiary hospital in sub Saharan Africa HOAJ, 2014 Vol.3(2)

20. Kigera JWM, Straetemans M, Vuhaka SK, Nagel IM, Naddumba EK Boer K. Is there an increased risk of post-operative surgical site infection after orthopaedic surgery in HIV patrients? A systematic review and Meta-analysis. PLOS ONE 2012; 8 (8):1-11.

21. Li X, Zhang $Q$, Zhao C, Zhao R. Wound complications in HIV-positive male patients with fractures after operations. Austin J HIV/AIDS Res 2014; 1 (1):1-3. 